\title{
CHASER
}

\section{An Innovative Satellite Mission Concept to Measure the Effects of Aerosols on Clouds and Climate}

\author{
by Nilton O. Rennó, Earle Williams, Daniel Rosenfeld, David G. Fischer, Jürgen Fischer, Tibor Kremic, \\ Arun Agrawal, Meinrat O. Andreae, Rosina Bierbaum, Richard Blakeslee, Anko Boerner, Neil Bowles, \\ Hugh Christian, Ann Cox, Jason Dunion, Akos Horvath, Xiangle Huang, Alexander Khain, \\ Stefan Kinne, Maria C. Lemos, Joyce E. Penner, Ulrich Pöschl, Johannes Quaas, Elena Seran, \\ Bjorn Stevens, Thomas Walati, and Thomas Wagner
}

CHASER proposes to revolutionize our understanding of the interactions of aerosols with clouds by making the first global survey of the fundamental physical entity linking them: activated cloud condensation nuclei.

T he formation of cloud droplets on aerosol particles, technically known as the activation of cloud condensation nuclei (CCN), is the fundamental process driving the interactions of aerosols with clouds and precipitation. Knowledge of these interactions is foundational to our understanding of weather and climate. The Intergovernmental Panel on Climate Change (IPCC) and the Decadal Survey (NRC 2007) indicate that the uncertainty in how clouds adjust to aerosol perturbations dominates the uncertainty in the overall quantification of the radiative forcing attributable to human activities. The Clouds, Hazards, and Aerosols Survey for Earth Researchers (CHASER) satellite mission concept responds to the IPCC and Decadal Survey concerns by studying the activation of CCN and their interactions with clouds and storms.

The CHASER satellite mission was developed to remotely sense quantities necessary for determining the interactions of aerosols with clouds and storms. The links between the Decadal Survey recommendations and the CHASER goals, science objectives, measurements, and instruments are described in Table 1. Measurements by current satellites allow a rough determination of profiles of cloud particle size but not of the activated CCN that seed them. CHASER will use an innovative technique (Freud et al. 2011; Freud and Rosenfeld 2012; Rosenfeld et al. 2012) and high-heritage (flown in a previous spaceflight mission) instruments to produce satellite-based remotely sensed observations of activated $\mathrm{CCN}$ and the properties of the clouds associated with them. CHASER will estimate updraft velocities at cloud base to calculate the number density of activated CCN as a function of the water vapor supersaturation. CHASER will determine the CCN concentration and cloud thermodynamic forcing (i.e., forcing caused by changes in the temperature and humidity of the boundary layer air) simultaneously, allowing their effects to be distinguished. Changes in the behavior of a group of weather systems in which only one of the quantities varies (a partial derivative of the intensity of the weather system with respect to the desirable quantity) will allow the determination of each effect statistically.

SCIENTIFIC BACKGROUND. Aerosols play an important role in cloud processes by providing nuclei for the condensation of water vapor into droplets. The nucleation of cloud droplets depends on the composition and size of the aerosol particles 
seeding these clouds and on the water vapor pressure affecting them (Seinfeld and Pandis 2006; Andreae and Rosenfeld 2008). An increase in the number of aerosol particles, known as $\mathrm{CCN}$, leads to an increase in the number of cloud droplets and a decrease in their size. The increase in cloud droplet number, in turn, increases cloud solar reflectance for a constant liquid water path (Twomey 1977) if the clouds are not optically thick.

Albrecht (1989) suggested that because the coalescence efficiency of small droplets is lower than that of larger droplets, aerosols decrease precipitation and increase cloud lifetime and area coverage. This idea is supported by aircraft measurements that indicate lower concentrations of aerosols in areas of broken marine stratocumulus clouds than in nearby overcast areas (Stevens et al. 2005; Petters et al. 2006; Savic-Jovcic and Stevens 2008; Wood et al. 2011). The cloud albedo effect is generally well accepted, whereas cloud lifetime and area coverage are recognized but are more difficult to measure and are less well understood. However, measurements suggest that this effect may be larger than the cloud albedo effect (Sekiguchi et al. 2003; Rosenfeld et al. 2006).

It has been hypothesized that convective clouds forming in clean environments with CCN $200 \mathrm{~cm}^{-3}$ distribute their liquid water into large droplets that can rain out before freezing ("warm rain"), inhibiting the development of thunderstorms. In contrast, it has been hypothesized that convective clouds forming in environments with $\mathrm{CCN} \sim 2,000 \mathrm{~cm}^{-3}$ contain a larger number of small droplets that increase their solar reflectance (Williams et al. 2002). According to the hypothesis, coalescence, and therefore the formation of warm rain, is inhibited in these clouds. The latent heat released when small droplets freeze aloft produces intense thunderstorms (Williams et al. 2002). CHASER will test these hypotheses by determining activated CCN and thermodynamic forcing as well as cloud growth and lightning flash rate (a metric of storm intensity).

It has been suggested that the effects of aerosols and thermodynamics on clouds can independently explain a surprisingly large number of weather phenomena (Williams et al. 2002; Williams and Stanfill 2002; Williams et al. 2005; Rosenfeld et al. 2008a). Examples include the dominance of lightning activity over continents, the dependence of lightning on temperature on several time scales, the dominance of clouds producing warm rain over oceans, the prevalence of large hail over polluted continents, the dominance of upper tropospheric ice processes in continental convective clouds, and the occasional onset of explosive lightning in hurricanes.

Why are thermodynamics and aerosol effects on moist convection so tightly interrelated and, at the same time, so poorly distinguished? The physical differences between land and ocean surfaces play a major role in accounting for this situation and may explain it via both thermodynamic and aerosol effects. Land surfaces possess lower heat capacity materials than the mobile liquid ocean water and, therefore, become relatively hotter given the same solar forcing. However, the land surface is also the primary source for aerosols (Andreae and Rosenfeld 2008; Andreae 2009). By estimating the effects of aerosols and thermodynamics on clouds and thunderstorms, CHASER allows their effects to be distinguished.

Calculations of aerosol-cloud interactions from current remote sensing data must extrapolate
Affiliations: Rennó, Huang, and Penner-Department of Atmospheric, Oceanic and Space Sciences, University of Michigan, Ann Arbor, Michigan; WILLIAMS-Department of Civil and Environmental Engineering, Massachusetts Institute of Technology, Cambridge, Massachusetts; Rosenfeld AND KHAIN-Hebrew University of Jerusalem, Jerusalem, Israel; D. G. FISCHER AND KREMICNASA Glenn Research Center, Cleveland, Ohio; J. FISCHER-Freie Universität Berlin, Berlin, Germany; Agrawal, Bierbaum, AND LemosSchool of Natural Resources and the Environment, University of Michigan, Ann Arbor, Michigan; ANDREAE AND PöschL一MaxPlanck-Institut für Chemie, Mainz, Germany; BLAKESLEE-NASA Marshall Space Flight Center, Huntsville, Alabama; BOERNER AND WALATI-Deutsches Zentrum für Luft- und Raumfahrt (DLR), Berlin, Germany; Bowles-Atmospheric, Oceanic and Planetary Physics, University of Oxford, Oxford, United Kingdom; CHRISTIAN-ESSC/ NSSTC, University of Alabama in Huntsville, Huntsville, Alabama; Cox-Orbital Sciences Corporation, Dulles, Virginia; DuNION-
Cooperative Institute for Marine and Atmospheric Studies, University of Miami, Miami, Florida; HoRvath, KInNE, AND SteVens-Max-PlanckInstitut für Meteorologie, Hamburg, Germany; QUAAS—Institute for Meteorology, Universität Leipzig, Leipzig, Germany; SeRANLATMOS, University of Paris VI, Paris, France; WAGNER — Institut für Umweltphysik, University of Heidelberg, Heidelberg, Germany CORRESPONDING AUTHOR: Nilton O. Rennó, 2455 Hayward Street, Department of Atmospheric, Oceanic and Space Sciences, University of Michigan, Ann Arbor, MI 48109-2143

E-mail: renno@alum.mit.edu

The abstract for this article can be found in this issue, following the table of contents.

DOI:10.1175/BAMS-D-II-00239.I

A supplement to this article is available online (I0.II75/BAMS-D-II-00239.2)

In final form 8 October 2012

()2013 American Meteorological Society 


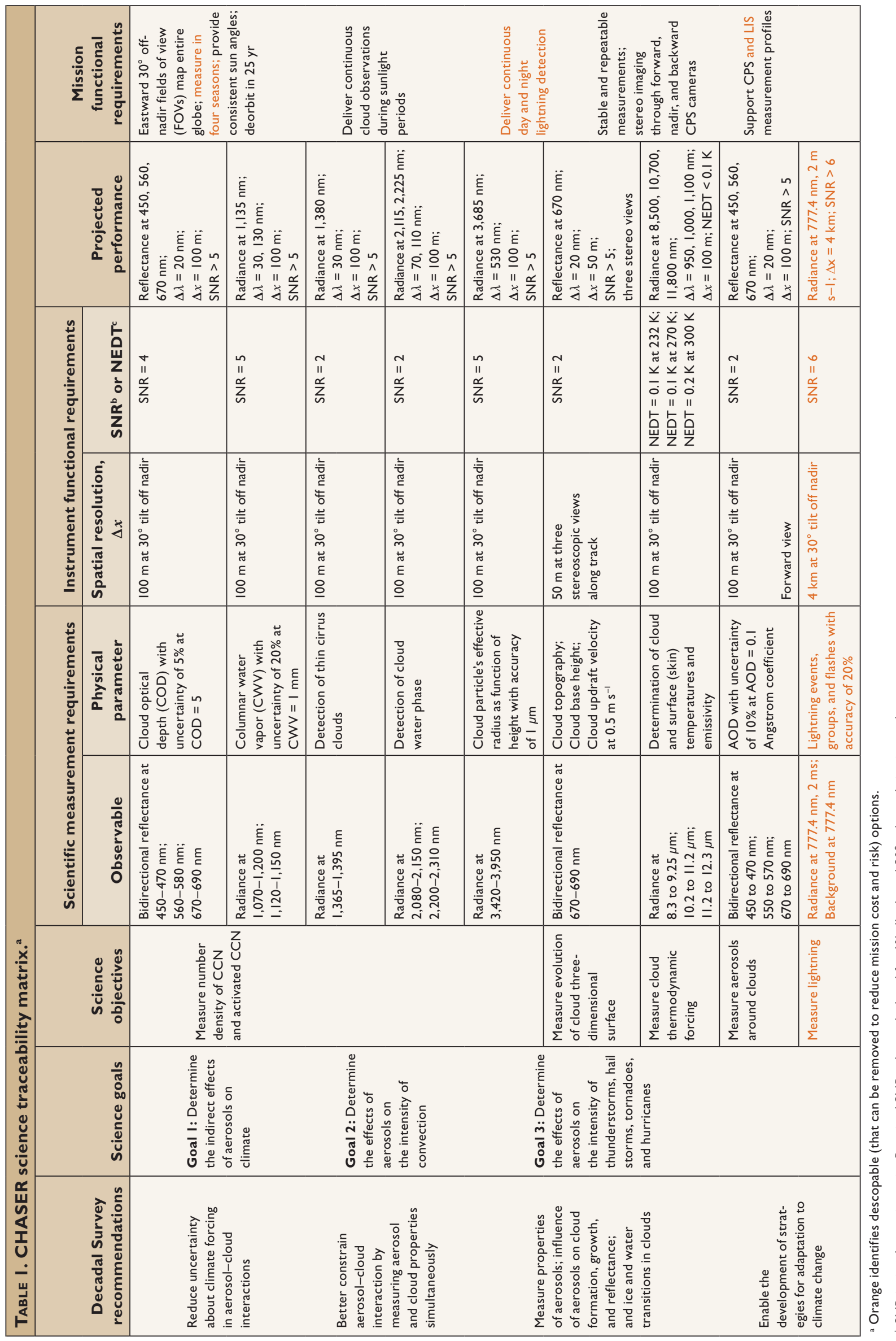

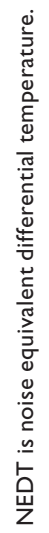


information of cloud droplet effective radius $\left(r_{e}\right)$ and the cloud droplet number density $\left(N_{d}\right)$ solely at the cloud top where they are measured. The fact that $N_{d}$ represents an average value that is affected by mixing of the cloudy air with its surroundings implies that it is only loosely correlated with the physical entity driving these interactions: the number density of activated CCN, here defined as $N_{a}$. Moreover, these calculations use empirical statistical relationships to relate measurements of aerosol optical depth (AOD) in the cloud-free air near the clouds to $N_{d}$ and $r_{e}$. These estimates are inaccurate because aerosols are not measured inside clouds; AOD is only weakly correlated with CCN (Andreae 2009), and AOD does not provide information about the vertical distribution of aerosols (Costantino and Bréon 2010). These inaccuracies decrease the inferred correlation of aerosol indirect effects with cloud properties and reduce the calculated value of aerosol indirect effects (Penner et al. 2011). CHASER's study of CCN and cloud microphysics will help shed light on these effects.

Traditionally, CCN are measured either in the laboratory or in the field using cloud chambers where water vapor supersaturation $(S)$ is controlled for the number of activated CCN to be counted as a function of $S$. CHASER's study of aerosol-cloud interactions treats clouds as natural chambers in which activated CCN are counted while $S$ is estimated simultaneously. The CHASER measurement technique is based on the fundamental principles described in the sidebar titled "What are the fundamental principles enabling the determination of the activated CCN?"

\section{CHASER GOALS AND OBJECTIVES.} CHASER's science goals are to determine 1) the indirect effects of aerosols on climate, 2) the effects of aerosols on the intensity of convection, and 3) the effects of aerosols on extreme weather events such as hailstorms, tornadoes, and hurricanes. CHASER's science objectives are to determine (i) the number density of activated CCN, (ii) the three-dimensional evolution of cloud surfaces, (iii) cloud thermodynamic forcing, (iv) aerosols around clouds, and (v) lightning.

CHASER will make the first global survey of $N_{a}$, the activated CCN spectrum, and the vertical profiles of cloud properties directly affecting climate (Fig. 1). Previous attempts to use satellite measurements to quantify the effects of aerosols on clouds, such as the cloud albedo feedback, rely on estimates of cloud droplet number concentration from measurements of $r_{e}$ at the cloud top and of the concentration of aerosols in nearby cloud-free areas (Sekiguchi et al. 2003; Marshak et al. 2008). The uncertainty in these calculations is due largely to a lack of simultaneous measurements of both the CCN concentration near the cloud base and other cloud properties. The limitations of previous approaches have been discussed extensively in the literature (Costantino and Bréon 2010; Penner et al. 2011; Marshak et al. 2006b; Quaas et al. 2008; Grandey and Stier 2010; McComiskey and Feingold 2008). CHASER's innovative technique will overcome these limitations.

\section{RELATIONSHIP TO PAST, CURRENT, AND FUTURE MISSIONS. CHASER will com- plement and transcend current National Aeronautics}

\section{HOW WILL CHASER HELP POLICY MAKERS?}

Ro esearch has shown that the perception of a high level Nof uncertainty in climate predictions is one of the main reasons why their use in decision making has lagged (Lemos and Rood 2010). It has also been suggested that the usability of climate knowledge can be enhanced through interaction between data producers and data users. This interaction improves the perception of knowledge fit (e.g., through visualization and customization) and enhances accessibility by improving understanding (Kirchhoff 20I0). CHASER will mitigate this problem by establishing a data application center for conducting science policy research focused on understanding the best ways to use, transfer, and communicate mission data to decision makers. The CHASER Data Application Center will support the visions of the National Research Council and the Decadal Survey for an integrated program of observations from space that secures practical benefits for humankind by developing data products for assessing risks due to severe weather and climate change.
The CHASER team will engage with stakeholders such as climate modelers, social scientists, and decision makers to increase the usability of mission data. The CHASER team will survey what data products are needed and how to manage and disseminate them to better meet this need. For example, the team will leverage resources (especially human and network) with organizations involved with climate information dissemination and brokering such as NOAA's Regional Integrated Sciences and Assessments (RISA) program (Lemos and Morehouse 2005). For close to 20 years, these programs have brokered climate knowledge between producers and users. CHASER will document potential uses of CHASER data by decision makers in responding to the impact of climate changes-such as hurricanes and flooding - and to foster networks of users that can enhance the usability of CHASERgenerated data. 
and Space Administration (NASA) Earth Science Missions studying aerosols, clouds, and thunderstorms. The Clouds and Earth's Radiant Energy System (CERES) measures solar and thermal radiation to study energy fluxes and cloud radiative effects, but its estimation of radiative fluxes does not include retrievals of aerosols simultaneously to study their effects on these fluxes. Indeed, CERES relies solely on the angular distribution model to convert radiance measurements at any viewing zenith angle into broadband radiative fluxes. The Moderate Resolution Imaging Spectroradiometer (MODIS) retrieves the properties of aerosols and clouds by making the

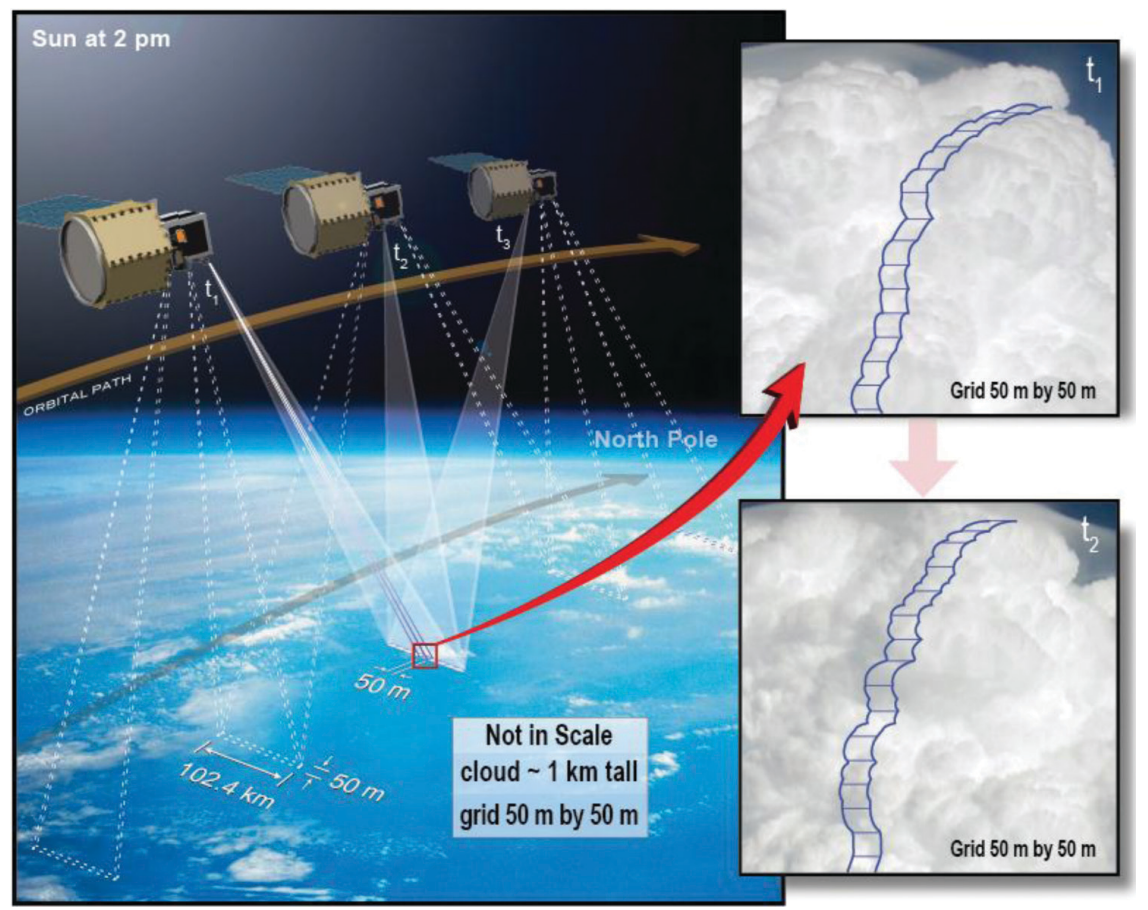

FIG. I. CHASER will determine vertical profiles of cloud parameters and lightning flashes pointing $30^{\circ}$ off track toward sun-illuminated cloud surfaces, which minimizes shadowing. Each MAI pixel is $50 \mathrm{~m} \times 50 \mathrm{~m}$, each MSI pixel is $100 \mathrm{~m}$ $\times 100 \mathrm{~m}$, and the swath width is $102.4 \mathrm{~km}$. The MAl pixels are represented by the blue overlays in the cloud images $50 \mathrm{~s}$ apart at $t_{1}$ and $t_{2}$.

assumption of one-dimensional plane parallel radiative transfer. Important three-dimensional effects such as the bluing of aerosols (Marshak et al. 2008; McComiskey and Feingold 2008) and biases in the retrieval of cloud droplet size (Lohmann et al. 2007; Zhang and Platnick 2011) are not accounted for. Moreover, these one-dimensional measurements can retrieve physical quantities only at the cloud top. The Multiangle Imaging SpectroRadiometer (MISR) uses multiangle, multispectral measurements to calculate aerosol optical depth, but it does not retrieve the microphysical properties of convective clouds. The Cloud-Aerosol Lidar and Infrared Pathfinder Satellite Observations (CALIPSO) provides information about aerosols as well as optically thin clouds, but it does not provide information on cloud particle sizes and concentrations. CloudSat measures the vertical structure of a cloud along a narrow swath (approximately $1 \mathrm{~km}$ ) across the satellite track, but it does not measure aerosols.

Measurements by current instruments do not provide the aerosol properties required to develop reliable estimates of their CCN supersaturation activation spectrum. However, measurements of AOD by MODIS, for example, can be used to complement CHASER rough estimates of CCN abundances (Andreae 2009). Further development of these capabilities could substantially improve global estimates of CCN abundances. None of the current satellites meet the requirements for estimating $N_{a}$ and the CCN spectrum. CHASER meets the requirements for the Decadal Survey recommendations for spacebased measurements of aerosol-cloud interaction in the decade 2010-20.

MEASUREMENT CONCEPT. The concept of using remote sensing to determine vertical profiles of cloud microphysics was proposed by Rosenfeld and Lensky (1998) and later refined by others (Rosenfeld 1999; Ramanathan et al. 2001; Rudich et al. 2002; Williams et al. 2002; Rosenfeld et al. 2008c). Cloud profiling by aircraft validated the concept (Andreae et al. 2004; Rosenfeld et al. 2008). Subsequently, Marshak et al. (2006a) and Martins et al. (2007) showed that high-resolution cloud profilers could retrieve $r_{e}$ and phase as a function of height, and they proposed an instrument to do it. Zinner et al. (2008) demonstrated the feasibility of this concept for cloud profilers with a resolution of $250 \mathrm{~m}$.

Brenguier et al. (2000) developed the idea of using vertical profiles of $r_{e}$ to calculate the value of $N_{a}$ at the base of shallow cumulus clouds. Freud et al. (2011) 
and Rosenfeld et al. (2012) generalized the idea to deeper clouds. They demonstrated that measurements of $N_{a}$ and updraft velocities could be used to calculate the CCN concentration in the boundary layer air feeding these clouds.
Rosenfeld et al. (2012) showed that the calculation of $N$ requires images with resolution of about $100 \mathrm{~m}$ to probe cloud protuberances. Images of lower resolution cannot resolve individual convective updrafts close to the cloud base with the required accuracy of about

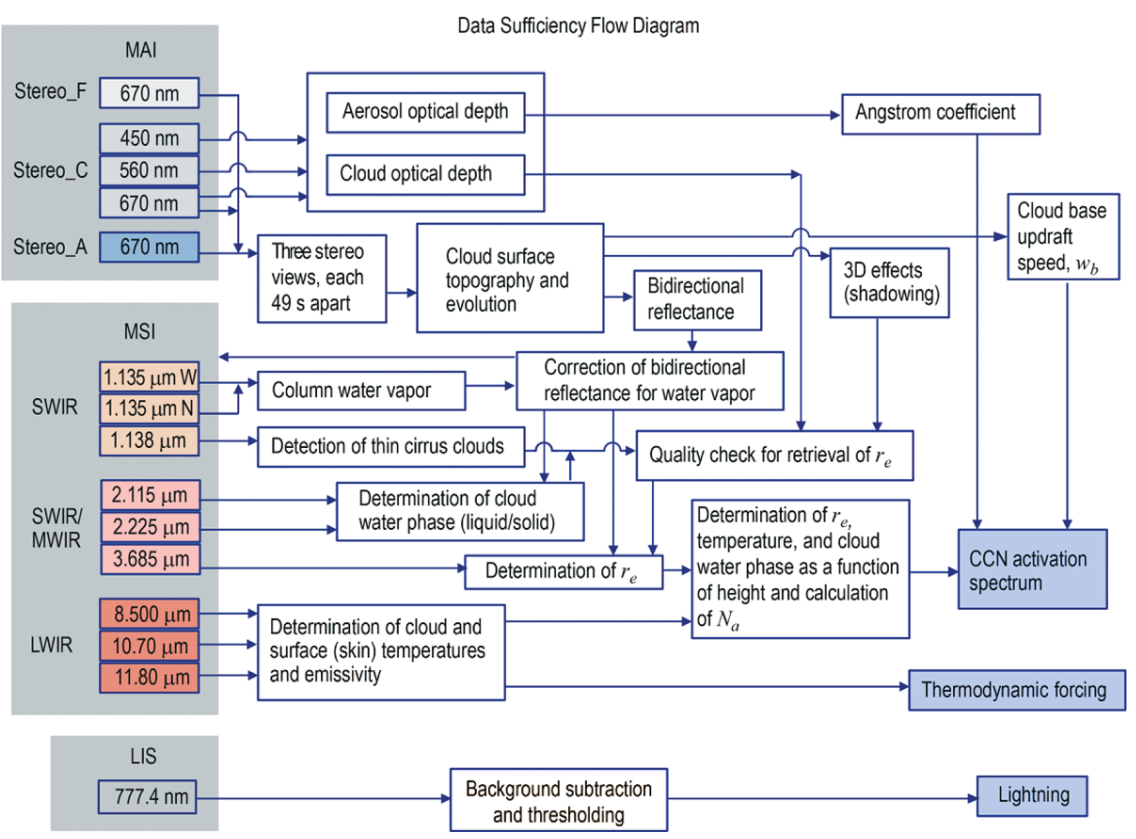

FIG. 2. CHASER's instruments yield measurements to produce all data products necessary to meet the mission science objectives described in this article ( $\mathrm{W}=$ wide band and $\mathbf{N}=$ narrow band).
$0.5 \mathrm{~m} \mathrm{~s}^{-1}$, and further increases in resolution do not improve the results because three-dimensional effects predominate (Rosenfeld et al. 2004). Table 1 and Fig. 2 indicate that CHASER meets these measurement requirements.

CHASER will determine vertical profiles of cloud parameters at 1400 local solar time by probing the sun-illuminated surfaces of convective clouds. The orbit and viewing geometry were chosen to provide global coverage while maximizing image resolution and minimizing shadowing.

CHASER will use a high-heritage Cloud
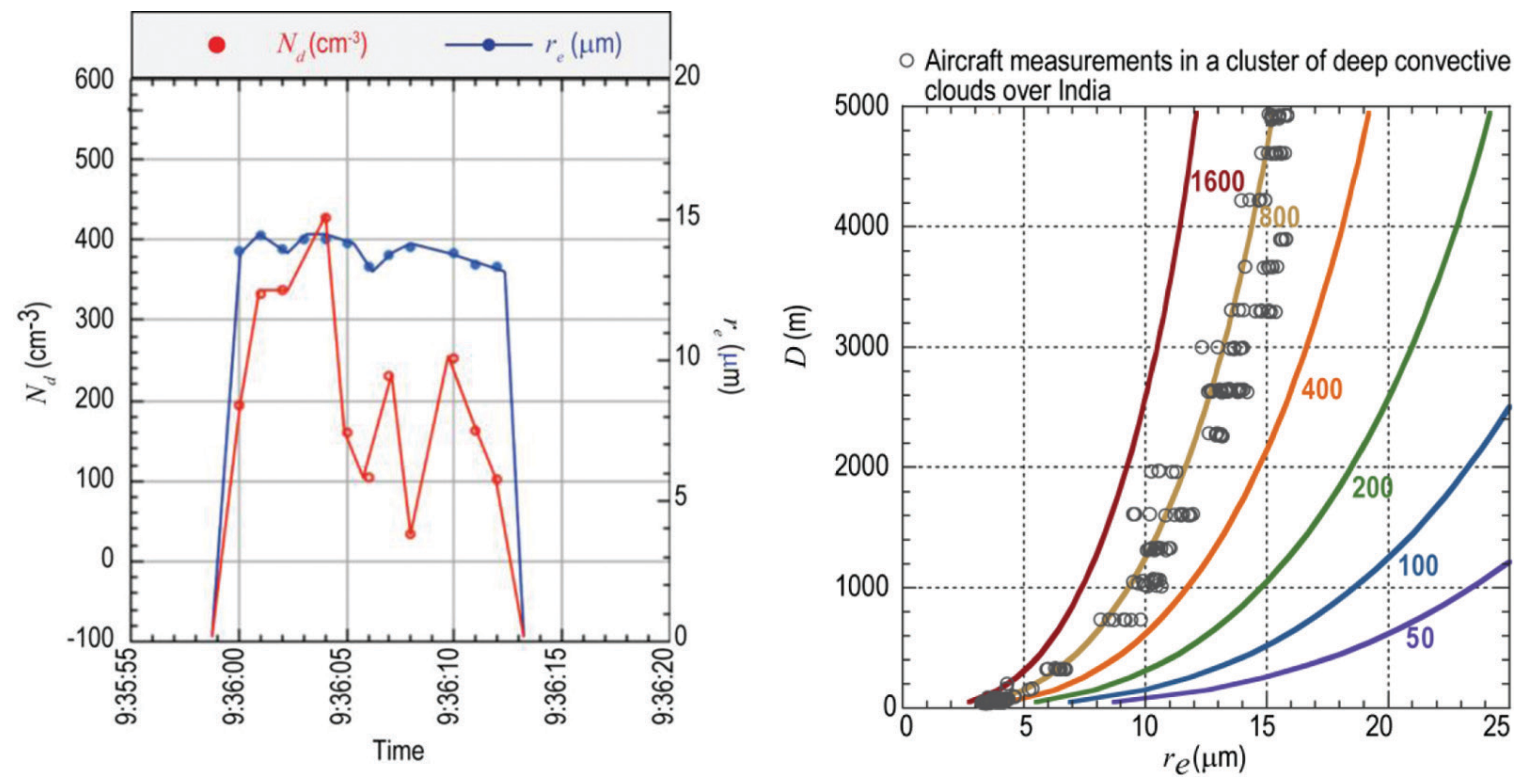

FIG. 3. (left) Values of $N_{d}$ and $r_{e}$ measured by an aircraft flying horizontally through a convective cloud at $D=3,400 \mathrm{~m}$ as described by Freud et al. (20II). The values of $N_{d}$ vary substantially, but the values of $r_{e}$ do not. (right) Relationship between $r_{e}$ and $D$ for various values of $N_{a}\left(\mathrm{~cm}^{-3}\right)$, where $r_{e}$ is calculated assuming that rising air parcels exhibit adiabatic liquid water content (Freud and Rosenfeld 20I2; Rosenfeld et al. 2012). The value derived from the profile of $r_{e}$ measured by the aircraft is $\mathbf{N}_{a}=610 \mathrm{~cm}^{-3}$, within $5 \%$ of the measured droplet concentration at cloud base. 
Profiler Suite (CPS) consisting of two instruments pointing $30^{\circ}$ off nadir across track toward sunilluminated surfaces on the east. The Multispectral Imager (MSI) consists of several spectrally diverse imagers with $100-\mathrm{m}$ resolution to probe activated CCN and determine the properties of clouds and their environment. The Multiangle Imager (MAI) consists of three visible imagers with 50-m resolution pointing forward, downward, and backward along the track as well as $30^{\circ}$ off nadir across track. Cloud properties and the evolution of cloud protuberances will be determined from MAI stereo images taken at times $t_{1}, t_{2}$, and $t_{3}$-each approximately $50 \mathrm{~s}$ apart (Fig. 1). The MAI and the MSI are high-heritage instruments based on Deutsches Zentrum für Luftund Raumfahrt (DLR)'s Bispectral Infrared Detection (BIRD), Technology Experiment Carrier-1 (TET-1), Berlin Infrared Optical System (BIROS), and Environmental Mapping and Analysis Program (EnMAP). CHASER will also detect lightning with a highheritage Lightning Imaging Sensor (LIS) (Buechler et al. 2011). The design and characteristics of MSI, MAI, and LIS are described in the supplementary material archived online (http://dx.doi.org//0.II75 /BAMS-D-II-00239.2).

The CHASER measurement technique relies on the fact that the variation of $r_{e}$ with distance above cloud base $(D)$ depends uniquely on the number density of the CCN activated to form these cloud droplets $\left(N_{a}\right)$ (Freud et al. 2011). That is, the number density of activated cloud condensation nuclei $\left(N_{a}\right)$ can be estimated from the vertical profile of cloud droplet effective radius $\left(r_{e}\right)$. Figure 3 shows that the dependence of $r_{e}$ on $D$ is robust and therefore can be used to determine $N_{a}$. The effects of mixing can be used to refine the calculation of $N_{a}$ (Freud et al. 2011; Freud and Rosenfeld 2012; Rosenfeld et al. 2012). Figure 2 indicates how CHASER's measurements of reflectance at various wavelengths will be used to retrieve cloud and aerosol quantities.

Since CHASER studies the three-dimensional evolution of clouds, the updraft velocities near cloud

\section{WHAT ARE THE FUNDAMENTAL PRINCIPLES ENABLING THE DETERMINATION OF THE ACTIVATED CCN?}

$\mathrm{T}^{\mathrm{h}}$ he number density of activated cloud condensation nuclei $\left(N_{c}\right)$ depends on aerosol size, chemical composition, and the water vapor supersaturation $(S)$ where nucleation occurs (cloud base). The liquid water content of a cloud parcel lifted adiabatically is $q_{\mathrm{La}}=4 / 3 \rho_{L} \pi r_{v}{ }_{v} N$, where $\rho_{L}$ is the density of liquid water and $r_{v}$ is the mean volume cloud droplet radius. Thus, the radius of the cloud droplets in this air parcel increases in proportion to the cube root of the adiabatic cloud liquid water content. Since, in an air parcel lifted adiabatically, $q_{\mathrm{La}}$ is a known function of the thermodynamic properties of the cloud base air (pressure, temperature, and humidity) and of the distance above the cloud base $(D)$, which are quantities inferred from CHASER measurements, $N_{a}$ can be calculated if $r_{v}$ is known.

Over larger volumes, the properties of cloudy air cannot be derived from adiabatic lifting, but the properties of smaller subcloud convective updrafts can. Paluch and Baumgardner (1989) showed that to a first-order approximation convective updrafts mix inhomogeneously with surrounding air to form subensembles of updrafts and downdrafts. This occurs because cloud droplets directly exposed to mixing with unsaturated air evaporate completely, thereby cooling the mixed air and forming downdrafts while leaving the original updraft and its cloud droplets little affected. The mixing decreases $N_{d}$ and $q_{L}$, but it does not affect the value of $r_{e}$ in the updraft. This process is illustrated by data from aircraft measurements shown in Fig. 3. Freud et al. (20II) estimated that the errors in $N_{a}$ caused by the deviation from inhomogeneous mixing vary between $5 \%$ and $20 \%$ and proposed a procedure to reduce them. In this procedure, an initial value of $N_{a}$ is calculated assuming inhomogeneous mixing and then it is corrected interactively until a value of $N_{a}$ that best fits the vertical profile of $r_{e}$ is found.

The value of $r_{\mathrm{e}}$ can be inferred from satellite measurements (Nakajima and King 1990), but $r_{v}$ cannot. Fortunately, aircraft measurements show that these two quantities are linearly related to each other (Freud et al. 20II) and, therefore, $r_{v}$ can be determined. This allows $N_{a}$ to be calculated by the following procedure: I) Measure $r_{e}$ as a function of $\left.D: r_{e}(D) .2\right)$ Use the linear relationship between $r_{v}$ and $r_{e}$ to calculate $\left.r_{v} \cdot 3\right)$ Use the relationship $N_{a}=3 /\left(4 \pi q_{L a} \rho_{L} r_{v}^{3}\right)$ to calculate $N_{a} \cdot 4$ ) Use measurements of the humidity of the air surrounding the clouds and empirical relationships derived from aircraft measurements (Freud et al. 201I) to refine the calculation of $N_{a}$. These procedures are illustrated in Fig. 3, where $r_{e}$ is calculated assuming that rising air parcels exhibit adiabatic liquid water content. For simplicity, the effects of mixing are ignored in the calculation.

Twomey (1959) showed that the value of $S$ in cloud updrafts is a function of the cooling rate or updraft velocity. By measuring the evolution of cloud protuberances between consecutive stereo image pairs obtained $50 \mathrm{~s}$ apart, CHASER will estimate updraft velocities at the cloud base and enable calculations of $N_{a}$ as a function of $S$. This is possible because the growth of cloud protuberances closely follows updrafts at the cloud base (Blyth et al. 2005). The determination of $N_{a}$ over a wide range of $S$ will provide the $\mathrm{CCN}$ spectrum - the concentration of particles that can become CCN when subjected to the range of $S$ expected over a range of cloud updraft speeds. 
base can be calculated and used to estimate the value of $S$. This is possible because $S$ is a function of the cooling rate and, therefore, of the updraft velocity (Twomey 1959). Calculations of $S$ and $N_{a}$ in convective updrafts of different intensities make possible the determination of the concentration of activated CCN as a function of $S$. This important quantity is referred to in the cloud physics literature as the $\mathrm{CCN}$ spectrum.

CONCLUDING REMARKS. In order to achieve its top science goals, CHASER will make global surveys of activated CCN simultaneously with the determination of the properties of the clouds affected by them. This requires measurements of the vertical profiles of the reflectance and the microphysical properties of incipient convective clouds (e.g., Freud et al. 2011; Rosenfeld et al. 2012). CHASER's sunsynchronous orbit (SSO) timed to early afternoon and its eastward viewing geometry were chosen to satisfy these requirements. If selected for funding, CHASER will reduce the uncertainty in our knowledge of the

\section{TESTING THE CHASER MEASUREMENT TECHNIQUE THROUGH AIRBORNE AND GROUND MEASUREMENTS}

n airborne instrument will be developed to test A the CHASER measurement technique and retrieval algorithms. Airborne in situ aerosol and cloud measurements will be used to evaluate the accuracy of the vertical profiles measured using the CHASER remote sensing technique. The U.S. Department of Energy (DOE) Atmospheric Radiation Measurement (ARM) sites in the Southern Great Plains (Oklahoma), the tropical western Pacific (with stations on the Nauru and Manus Islands and in Darwin, Australia-farther west), and on the North Slope of Alaska (Jefferson 20II) will also be used to validate the CHASER measurements. The ARM sites are located in regions covering the typical aerosol concentrations from clean maritime to polluted continental environments. The CHASER team will propose to fly its airborne instrument over all ARM sites. Comparisons of $N_{a}$ between airborne and groundbased sensors will be conducted while clouds develop in the vicinity of ground stations and, therefore, ingest boundary layer air that is being sampled simultaneously by the CHASER airborne instrument and in situ measurements of aerosols at the surface.

The ARM CCN measurements cover CCN concentrations over a range of supersaturation from $<0.1 \%$ to $>1 \%$ (Jefferson 20II), which is similar to the CHASER measurement range. The Southern Great Plains site has complementary information on aerosol size, composition, and relative humidity that can be used to predict the CCN. interaction of aerosols with clouds and precipitation by making global surveys capable of distinguishing the effects of aerosols from those of thermodynamics in clouds and storms.

ACKNOWLEDGMENTS. We thank NASA Glenn Research Center, the University of Michigan, the Deutsches Zentrum für Luft- und Raumfahrt (DLR), the Israeli Space Agency, and Orbital Sciences Corporation for supporting the development of the CHASER mission concept. Many engineers, managers, and technical staff played key roles on the development of the CHASER mission concept. N. Rennó was partially supported by NSF Award AGS 1118467.

\section{REFERENCES}

Albrecht, B. A., 1989: Aerosols, cloud microphysics, and fractional cloudiness. Science, 245, 1227-1230, doi:10.1126/science.245.4923.1227.

Andreae, M. O., 2009: Correlation between cloud condensation nuclei concentration and aerosol optical thickness in remote and polluted regions. Atmos. Chem. Phys., 9, 543-556.

—, and D. Rosenfeld, 2008: Aerosol-cloud-precipitation interactions. Part 1 . The nature and sources of cloud-active aerosols. Earth-Sci. Rev., 89, 13-41.

— - — P. Artaxo, A. A. Costa, G. P. Frank, K. M. Longo, and M. A. F. Silva-Dias, 2004: Smoking rain clouds over the Amazon. Science, 303, 1337-1342.

Blyth, A. M., S. G. Lasher-Trapp, and W. A. Cooper, 2005: A study of thermals in cumulus clouds. Quart. J. Roy. Meteor. Soc., 131, 1171-1190, doi:10.1256/ qj.03.180.

Brenguier, J.-L., H. Pawlowska, L. Schüller, R. Preusker, J. Fischer, and Y. Fouquart, 2000: Radiative properties of boundary layer clouds: Droplet effective radius versus number concentration. J. Atmos. Sci., 57, 803-821.

Buechler, D. E., H. J. Christian, W. J. Koshak, and S. J. Goodman, 2011: Assessing the lifetime performance of the Lightning Imaging Sensor (LIS): Implications for the Geostationary Lightning Mapper (GLM). Proc. XIV Int. Conf. on Atmospheric Electricity, Rio de Janeiro, Brazil, International Commission on Atmospheric Electricity.

Costantino, L., and F. M. Bréon, 2010: Analysis of aerosol-cloud interaction from multi-sensor satellite observations. Geophys. Res. Lett., 37, L11801, doi:10.1029/2009GL041828.

Freud, E., and D. Rosenfeld, 2012: Linear relation between convective cloud drop number concentration and depth for rain initiation. J. Geophys. Res., 117, D02207, doi:10.1029/2011JD016457. 
— - — , and J. R. Kulkarni, 2011: Resolving both entrainment-mixing and number of activated CCN in deep convective clouds. Atmos. Chem. Phys., 11, 12 887-12 900, doi:10.5194/acp-11-12887-2011.

Grandey, B. S., and P. Stier, 2010: A critical look at spatial scale choices in satellite-based aerosol indirect effect studies. Atmos. Chem. Phys., 10, 11 459-11 470, doi:10.5194/acp-10-11459-2010.

Jefferson, A., 2011: Aerosol observing system (AOS) handbook. U.S. Department of Energy, Office of Science Tech. Rep. DOE/SC-ARM/TR-014, 32 pp.

Kirchhoff, C. J., 2010: Integrating science and policy: Climate change assessments and water resources management. Ph.D. dissertation, University of Michigan, $293 \mathrm{pp}$.

Lemos, M. C., and B. J. Morehouse, 2005: The coproduction of science and policy in integrated climate assessments. Global Environ. Change, 15, 57-68.

— - and R. B. Rood, 2010: Climate projections and their impact on policy and practice. Wiley Interdiscip. Rev.: Climate Change, 1, 670-682.

Lohmann, U., J. Quaas, S. Kinne, and J. Feichter, 2007: Different approaches for constraining global climate models of the anthropogenic indirect aerosol effect. Bull. Amer. Meteor. Soc., 88, 243-249.

Marshak, A., J. V. Martins, V. Zubko, and Y. J. Kaufman, 2006a: What does reflection from cloud sides tell us about vertical distribution of cloud droplet sizes. Atmos. Chem. Phys., 6, 5295-5305.

—, S. Platnick, T. Várnai, G. Wen, and R. F. Cahalan, 2006b: Impact of three-dimensional radiative effects on satellite retrievals of cloud droplet sizes. J. Geophys. Res., 111, D09207, doi:10.1029/2005JD006686.

— , G. Y. Wen, J. A. Coakley Jr., L. A. Remer, N. G. Loeb, and R. F. Cahalan, 2008: A simple model for the cloud adjacency effect and the apparent bluing of aerosols near clouds. J. Geophys. Res., 113, D14S17, doi:10.1029/2007JD009196.

Martins, J. V., and Coauthors, 2007: Remote sensing the vertical profile of cloud droplet effective radius, thermodynamic phase, and temperature. Atmos. Chem. Phys. Discuss., 7, 4481-4519.

McComiskey, A., and G. Feingold, 2008: Quantifying error in the radiative forcing of the first aerosol indirect effect. Geophys. Res. Lett., 35, L02810, doi:10.1029/2007GL032667.

Nakajima, T., and M. D. King, 1990: Determination of the optical thickness and effective particle radius of clouds from reflected solar radiation measurements. Part I: Theory. J. Atmos. Sci., 47, 1878-1893.

NRC, 2007: Earth Science and Applications from Space: National Imperatives for the Next Decade and Beyond. National Academies Press, 456 pp.
Paluch, I. R., and D. Baumgardner, 1989: Entrainment and fine scale mixing in a continental convective cloud. J. Atmos. Sci., 46, 261-278.

Penner, J. E., L. Xu, and M. Wang, 2011: Satellite methods underestimate indirect climate forcing by aerosols. Proc. Natl. Acad. Sci. USA, 108, $13404-$ 13408, doi:10.1073/pnas.1018526108.

Petters, M. D., J. R. Snider, B. Stevens, G. Vali, I. Faloona, and L. M. Russell, 2006: Accumulation mode aerosol, pockets of open cells, and particle nucleation in the remote subtropical Pacific marine boundary layer. J. Geophys. Res., 111, D02206, doi:10.1029/2004JD005694.

Quaas, J., O. Boucher, N. Bellouin, and S. Kinne, 2008: Satellite-based estimate of the direct and indirect aerosol climate forcing. J. Geophys. Res., 113, D05204, doi:10.1029/2007JD008962.

Ramanathan, V., P. J. Crutzen, J. T. Kiehl, and D. Rosenfeld, 2001: Aerosols, climate and the hydrological cycle. Science, 294, 2119-2124.

Rosenfeld, D., 1999: TRMM observed first direct evidence of smoke from forest fires inhibiting rainfall. Geophys. Res. Lett., 26, 3105-3108.

_- and I. M. Lensky, 1998: Satellite-based insights into precipitation formation processes in continental and maritime convective clouds. Bull. Amer. Meteor. Soc., 79, 2457-2476.

— E. Cattani, S. Melani, and V. Levizzani, 2004: Considerations on daylight operation of 1.6- versus 3.7- $\mu \mathrm{m}$ channel on NOAA and METOP satellites. Bull. Amer. Meteor. Soc., 85, 873-881.

—, Y. Kaufman, and I. Koren, 2006: Switching cloud cover and dynamical regimes from open to closed Benard cells in response to aerosols suppressing precipitation. Atmos. Chem. Phys., 6, 2503-2511.

—, U. Lohmann, G. B. Raga, C. D. O’Dowd, M. Kulmata, A. Reissell, and M. O. Andreae, 2008a: Flood or drought: How do aerosols affect precipitation? Science, 321, 1309-1313.

— , W. L. Woodley, D. Axisa, E. Freud, J. G. Hudson, and A. Givati, 2008b: Aircraft measurements of the impacts of pollution aerosols on clouds and precipitation over the Sierra Nevada. J. Geophys. Res., 113, D15203, doi:10.1029/2007JD009544.

— - _ A. Lerner, G. Kelman, and D. T. Lindsey, 2008c: Satellite detection of severe convective storms by their retrieved vertical profiles of cloud particle effective radius and thermodynamic phase. J. Geophys. Res., 113, D04208, doi:10.1029/2007JD008600.

Rosenfeld D., E. Williams, M. O. Andreae, E. Freud, U. Pöschl, and N. O. Rennó, 2012: The scientific basis for a satellite mission to retrieve $\mathrm{CCN}$ concentrations and their impacts on convective clouds. Atmos. Meas. Tech., 5, 2039-2055, doi:10.5194/amt-5-2039-2012. 
Rudich, Y., D. Rosenfeld, and O. Khersonsky, 2002: Treating clouds with a grain of salt. Geophys. Res. Lett., 29, 2060, doi:10.1029/2002GL016055.

Savic-Jovcic, V., and B. Stevens, 2008: The structure and mesoscale organization of precipitating stratocumulus. J. Atmos. Sci., 65, 1587-1605.

Seinfeld, J. H., and S. N. Pandis, 2006: Atmospheric Chemistry and Physics: From Air Pollution to Climate Change. 2nd ed. Wiley, 1203 pp.

Sekiguchi, M., T. Nakajima, K. Suzuki, K. Kawamoto, A. Higurashi, D. Rosenfeld, I. Sano, and S. Mukai, 2003: A study of the direct and indirect effects of aerosols using global satellite data sets of aerosol and cloud parameters. J. Geophys. Res., 108, 4699, doi:10.1029/2002JD003359.

Stevens, B., G. Vali, K. Comstock, R. Wood, M. VanZanten, P. H. Austin, C. S. Bretherton, and D. H. Lenschow, 2005: Pockets of open cells (POCs) and drizzle in marine stratocumulus. Bull. Amer. Meteor. Soc., 86, 51-57.

Twomey, S., 1959: The nuclei of natural cloud formation: The supersaturation in natural clouds and the variation of cloud drops concentrations. Geofis. Pura. Appl., 43, 243-249.

- 1977: The influence of pollution on the short wave albedo of clouds. J. Atmos. Sci., 34, 1149-1152.
Williams, E., and S. Stanfill, 2002: The physical origin of the land-ocean contrast in lightning activity. $C$. R. Phys., 3, 1277-1292.

— , and Coauthors, 2002: Contrasting convective regimes over the Amazon: Implications for cloud electrification. J. Geophys. Res., 107, 8082, doi:10.1029/2001JD000380.

—, V. C. Mushtak, D. Rosenfeld, S. J. Goodman, and D. J. Boccippio, 2005: Thermodynamic conditions favorable to superlative thunderstorm updraft, mixed phase microphysics and lightning flash rate. Atmos. Res., 76, 288-306.

Wood, R., and Coauthors, 2011: The VAMOS OceanCloud-Atmosphere-Land Study Regional Experiment (VOCALS-REx): Goals, platforms, and field operations. Atmos. Chem. Phys., 11, 627-654.

Zhang, Z., and S. Platnick, 2011: An assessment of differences between cloud effective particle radius retrievals for marine water clouds from three MODIS spectral bands. J. Geophys. Res., 116, D20215, doi:10.1029/2011JD016216.

Zinner, T., A. Marshak, S. Lang, J. V. Martins, and B. Mayer, 2008: Remote sensing of cloud sides of deep convection: Towards a three-dimensional retrieval of cloud particle size profiles. Atmos. Chem. Phys., 8, 4741-4757.

\section{NEW! PRINT \& CD FORMATS}

"Professor Lackmann has prepared an excellent synthesis of quintessential modern midlatitude synoptic-dynamic meteorology."

- LANCE BOSART, Distinguished Professor, Department of Atmospheric and Environmental Sciences, The University of Albany, State University of New York

\section{Midlatitude Synoptic Meteorology: Dynamics, Analysis, and Forecasting} GARY LACKMANN

The past decade has been characterized by remarkable advances in meteorological observation, computing techniques, and datavisualization technology. Midlatitude Synoptic Meteorologylinks theoretical concepts to modern technology and facilitates the meaningful application of concepts, theories, and techniques using real data. As such, it both serves those planning careers in meteorological research and weather prediction and provides

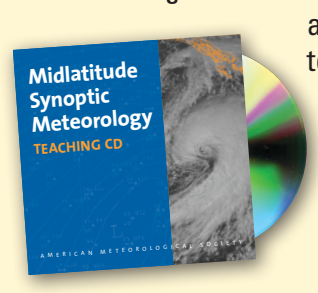
a template for the application of modern technology in the classroom.

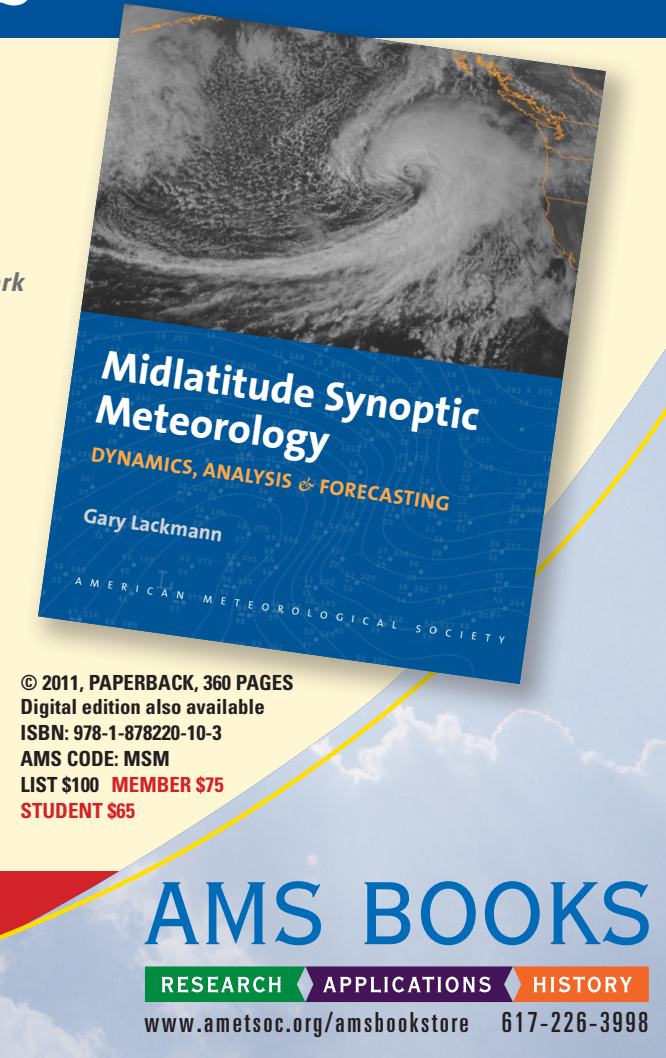

Instructors: Midlatitude Synoptic Teaching CD, containing over 1,000 lecture slides, is now available! 